Article

\title{
Conversion of Lignocellulosic Corn Agro-Waste into Cellulose Derivative and Its Potential Application as Pharmaceutical Excipient
}

\author{
Md. Saifur Rahman 1,2, Md. Ibrahim H. Mondal ${ }^{1, *}$, Mst. Sarmina Yeasmin ${ }^{3}$, M. Abu Sayeed ${ }^{1}$, \\ Md Ashraf Hossain 4 (D) and Mohammad Boshir Ahmed 1,2,5,*(D) \\ 1 Department of Applied Chemistry and Chemical Engineering, University of Rajshahi, Rajshahi 6205, \\ Bangladesh; saifurrahman@gist.ac.kr (M.S.R.); drmdabusayeed@gmail.com (M.A.S.) \\ 2 Gwangju Institute of Science and Technology, School of Materials Science and Engineering, \\ Gwangju 61005, Korea \\ 3 Bangladesh Council of Scientific and Industrial Research Laboratories, Rajshahi 6206, Bangladesh; \\ lisabcsir@yahoo.com \\ 4 Department of Materials Science and Engineering, Korea University, Seoul 02841, Korea; \\ ashraf3521@gmail.com \\ 5 Center for Green Technologies, School of Civil and Environmental Engineering, \\ University of Technology Sydney, 15, Broadway, Sydney, NSW 2007, Australia \\ * Correspondence: mihmondal@gmail.com (M.I.H.M.); mohammad.ahmed@gist.ac.kr (M.B.A.)
}

Received: 26 May 2020; Accepted: 15 June 2020; Published: 19 June 2020

\begin{abstract}
Lignocellulosic biomass is widely grown in many agricultural-based countries. These are typically incinerated or discarded in open spaces, which further may cause severe health and environmental problems. Hence, the proper utilization and conversion of different parts of lignocellulosic biomasses (e.g., corn wastes derived leave, cob, stalk, and husk) into value-added materials could be a promising way of protecting both health and environments. In addition, they have high-potential for myriads applications (e.g., pharmaceuticals, cosmetics, textiles, and so on). In this context, herein, we isolated holocellulose (a mixture of alpha $\alpha$, beta $\beta$, and gamma $\gamma$ cellulose) from corn waste, and then it was converted into carboxymethyl cellulose (CMC). Subsequently, the prepared CMC was evaluated successfully to be used as a pharmaceutical excipient. Different characterization tools were employed for structural, morphological, and thermal properties of the extracted holocellulose and synthesized CMC. Results showed that the highest yield of CMC was obtained $187.5 \%$ along with the highest degree of substitution (DS i.e., 1.83) in a single stage (i.e., size reduction technique) with the lowest particle size of holocellulose $(100 \mu \mathrm{m})$. This happened due to the use of a single stage instead of multiple stages. Finally, extracted CMC was successfully used as a pharmaceutical excipient with promising results compared to commercially available pharmaceutical-grade CMC.
\end{abstract}

Keywords: lignocellulosic biomass; holocellulose; CMC; degree of substitution; excipient

\section{Introduction}

Lignocellulosic biomass is the most abundant resource in nature with immense potential for numerous applications [1]. Among different lignocellulosic biomasses, agricultural waste-based biomass consists of cellulose (35-50\%), hemicellulose (20-35\%), and lignin (10-25\%) [2]. Corn (Zea mays) is one of the abundant cereal crops that is cultivated extensively across the world, which produces huge lignocellulosic biomass. The world's total corn production was 985,889.6 (1000 MT) from 2012 to 2017. USA was the top country for producing corn in the period of 2012-2017 with the production capacity of 343,167.8 (1000 MT), followed by the China, Brazil, Argentina, and Ukraine which produced 
216,787.0, 82,400.0, 30,550.0, 26,321.0 (1000 MT) of corn, respectively [3]. Therefore, the processing of matured corn can produce large amount of waste. It is estimated that $1 \mathrm{~kg}$ of dry corn may yield up to $150 \mathrm{~g}$ of cobs, $220 \mathrm{~g}$ of leaves, and $50 \mathrm{~g}$ of stalks [4]. However, corn wastes namely leave, cob, stalk, and husk are the major biomass matters that often remain unutilized in the harvested fields. Not only are these corn wastes being used as a cooking fuel in some rural areas of many countries, but also often they are causing environmental problems due to inapt waste control such as on-site burning as well as landfilling. On the other hand, wastes from corn contain good quality cellulosic matters in their cell walls. Generally, cellulose is a linear and high molecular weight polymer that neither melts nor dissolves readily in water and many organic solvents. This characteristic makes cellulose ineffective in most of the industrial uses. Notwithstanding, cellulose can be transformed into valuable chemical feedstock (e.g., ethanol, lactic acid, furfural, and fermentable sugars including glucose and xylose) as it is susceptible to chemical and enzymatic derivatization reactions $[5,6]$. Cellulose contains three -OH groups in each of its anhydroglucose units. Among them, primary - $\mathrm{OH}$ at $\mathrm{C}-6$ and two secondary ones at $\mathrm{C}-2$ and $\mathrm{C}-3$ can take part in typical reactions such as esterification, etherification, and oxidation. Cellulose derivatives have been obtained by reacting to some (or all) - $\mathrm{OH}$ groups of anhydroglucose units $[6,7]$. Carboxymethylation of cellulose is a common conversion process which provides versatile water-swellable or water-soluble polymers and intermediates with variable characteristics [8,9].

Carboxymethyl cellulose (CMC) is produced through the reaction between alkali cellulose swollen in aqueous $\mathrm{NaOH}$ and monochloroacetic acid in the surplus of alcohol (Figure 1) [10]. Hydroxyl groups of the anhydrous glucose unit (AGU) are substituted by the sodium carboxymethyl groups in C-2, C-3, and C-6, of which substitution slightly dominates at C-2 position [11]. CMC has been synthesized by many researchers from different cellulosic sources such as paper sludge, hyacinth, wood residue, cotton linters, and bagasse [12-14]. Due to the polyelectrolyte character of CMC, it has many applications, such as being widely used in the food industry, detergents, cosmetics, pharmaceuticals, textiles, paper, adhesives, and ceramic industries [15]. The degree of substitution (DS) is considered a significant property of CMC particularly for its solubility in water, and the highest theoretical DS of CMC is considered as 3. It is reported that commercially available CMC has a DS value of 0.4 to 1.5 [16]. However, to achieve higher DS of CMC, several parameters such as the solvent system, the concentration of $\mathrm{NaOH}$, monochloroacetic acid (MCA), temperature, reaction time, and the different steps of carboxymethylation need to tune properly [17]. Generally, in every case, several steps have been performed to gain the higher DS. Therefore, an alternative approach such as minimization of steps to get higher DS is preferable.

$\mathrm{CMC}$ is an anionic derivative that is being largely used in oral, ophthalmic, injectable, and topical pharmaceutical formulations as an excipient. For solid dosage forms, CMC is used primarily as a binder or matrix former. When CMC is used as a binder, then it yields softer granules with good compressibility which form tough tablets with moderate strength [18]. On the other hand, commercially available microcrystalline cellulose-based excipients are extracted from hardwoods and also from purified cotton. Therefore, it is considered an expensive process that can further trigger investigations of finding cheaper resources for similar excipients preparation [19]. To the best of our knowledge, no report has been found in literature where a pharmaceutical excipient was prepared from the corn wastes based on lignocellulosic biomass. Henceforth, extracting CMC as well as excipient from the lignocellulosic agriculture waste (i.e., corn waste) could be considered an effective way for the reduction of production costs as well as process barriers as these biomasses are widely available and free of cost or at a very negligible price. In addition, such kind of low-cost material i.e., CMC can be further used to produce tablets at an industrial scale.

Hence, the main objective of this study is to extract CMC from low-cost corn wastes with higher DS by the utilization of a single-stage size-reduction method for lowering the extraction cost. The subsequent objective of this study is to use the synthesized CMC as a pharmaceutical excipient by testing its feasibility by performing different characterizations. 


\section{Material and Methods}

\subsection{Materials}

Corn wastes (Zea mays) including leaves, cob, stalk, and husk were collected in the harvesting season (i.e., June-July) from the Wheat Research Center Rajshahi, Rajshahi Division, Bangladesh. All the chemicals such as pharmaceutical excipient grade CMC (commercial), sodium hydroxide, monochloroacetic acid (MCA), acetic acid, ammonium oxalate, sulfuric acid, and hydrochloric acid were purchased from Sigma Aldrich, Bangladesh, and they were in the highest purity.

\subsection{Preparation of Sample}

Defective parts and foreign materials from the corn wastes were removed, followed by cutting into small pieces and dried in sunlight for several days to minimize the intrinsic moisture. The corn leave, cob, stalk, and husk were dried in the oven (FC-610, Toyo Seisakusho Co., Ltd., Chiba, Japan) at $105^{\circ} \mathrm{C}$ for several hours and grounded into powder using a disk mill (FFC-15). Later, the powder was screened into three different particle sizes $(100,400$, and $700 \mu \mathrm{m})$ by using a GFL Orbital Shaker (Model: 3017, Germany) and stored in a silica-containing desiccator for further use.

\subsection{Estimation of Fatty and Waxy Matters, Pectic Substances, and Lignin}

The dried powder sample was immersed in n-hexane- ethanol mixture in the solid to liquor ratio of 2: 200 for $10 \mathrm{~h}$. The suspension was then filtered and washed with the residue with the fresh n-hexane-ethanol mixture. After drying the residue, fatty and waxy matters were calculated using the following formula.

$$
\% \text { of fatty and waxy matters }=\frac{y \times 100}{x},
$$

where $y$ is the loss in weight and $x$ is the initial weight of the sample. The dewaxed and defatted powder was then heated with an ammonium oxalate solution $(0.5 \% w / v))$ in a liquor ratio of $0.1: 10$ at $80^{\circ} \mathrm{C}$ for 3 consecutive days in a heating mantle. The level of the solution kept constant by adding hot DI water simultaneously. Finally, the suspension was filtered and the residue was washed with DI water and dried at $105^{\circ} \mathrm{C}$ for getting pectic matters percentages:

$$
\% \text { of pectic matters }=\frac{y \times 100}{x} .
$$

The dewaxed and depectinized dried powder was then treated with $72 \%$ sulfuric acid with solid to acid ratio of 1:15 at ambient condition. The mixture was kept for $1.0 \mathrm{~h}$ and diluted by DI water up to $3 \%$ acid solution. Subsequently, the mixture was refluxed for $4.0 \mathrm{~h}$ and kept overnight. The mixture was filtered and washed thoroughly with hot DI water and the residue dried until reaching the constant weight at $105^{\circ} \mathrm{C}$. The residue was considered as lignin, and the powdered sample from the filtrate was the delignified sample [20].

\subsection{Isolation of Holocellulose}

Holocellulose was isolated with a slight modification of the previously reported method [20]. Briefly, a suitable amount of dewaxed and depectinized powder corn wastes were treated with a $0.7 \%$ $\mathrm{NaClO}_{2}$ solution at $\mathrm{pH} 4$, and at $90-95^{\circ} \mathrm{C}$ for 90 min with a liquor ratio of 1:80 (w/v). After being washed with DI water, chlorite holocellulose was treated with a $0.2 \% \mathrm{Na}_{2} \mathrm{~S}_{2} \mathrm{O}_{5}$ solution for $15 \mathrm{~min}$. Subsequently, the holocellulose containing solution was again filtered and washed thoroughly with distilled water, and finally dried at $60{ }^{\circ} \mathrm{C}$ to get the holocellulose.

\subsection{Estimation of $\alpha$-Cellulose and Hemicellulose ( $\beta$ and $\gamma$-Celluloses)}

The $\alpha$-cellulose and hemicellulose amount were determined to measure the total quantity in corn wastes [20]. Briefly, $1.0 \mathrm{~g}$ of the dried chlorite holocellulose was treated with an $18 \% \mathrm{NaOH}(w / v)$ solution for $2 \mathrm{~h}$ in the ratio of 1:100 (w/v). The mixture was then filtered and washed thoroughly with 
$2 \%$ acetic acid solution, followed by hot water. The residue was dried at $105^{\circ} \mathrm{C}$ until reaching constant weight. The dried residue (i.e., $\alpha$-cellulose) was deducted from the weight of the holocellulose to estimate the amount of hemicellulose.

An equal volume of filtrate and $3 \mathrm{~N} \mathrm{H}_{2} \mathrm{SO}_{4}$ was mixed and placed in a water bath for several minutes at $90^{\circ} \mathrm{C}$ to coagulate the $\beta$-cellulose. The mixture was kept for $12 \mathrm{~h}$ to settle the precipitate. Afterward, the precipitate was separated and dried at $105^{\circ} \mathrm{C}$ to obtain $\beta$-cellulose. Finally, the $\gamma$-cellulose was estimated by deducting the amount of $\alpha$-cellulose and $\beta$-cellulose from the initial weight of the holocellulose. Here, diluted acids were used to extract as well as estimate the components of holocellulose from the lignocellulosic wastes due to its economic and environmental feasibility [21].

\subsection{Conversion of Holocellulose into Carboxymethyl Cellulose}

The general schematic diagram and synthesis route of $\mathrm{CMC}$ from the holocellulose of corn wastes is depicted in Figure 1. The synthesis of CMC includes two consecutive steps namely, alkalization and etherification. During alkalization, holocellulose was suspended in ethanol, and $30 \%(w / v) \mathrm{NaOH}$ was added slowly for half an hour with vigorous stirring at room temperature, and the stirring was continued for an hour. In the etherification step, MCA (120\%) was added gently to the slurry before placing into the water bath at $50^{\circ} \mathrm{C}$ and heated for $3.6 \mathrm{~h}$ with intermittent stirring. The synthesized CMC was filtered and washed with $70 \%(v / v)$ alcohol to minimize the unwanted leftover and dried at $65^{\circ} \mathrm{C}$.

The outline of the mechanism for preparing CMC from holocellulose of corn wastes followed by two consecutive steps including basification as well as etherification are documented in Figure 1.
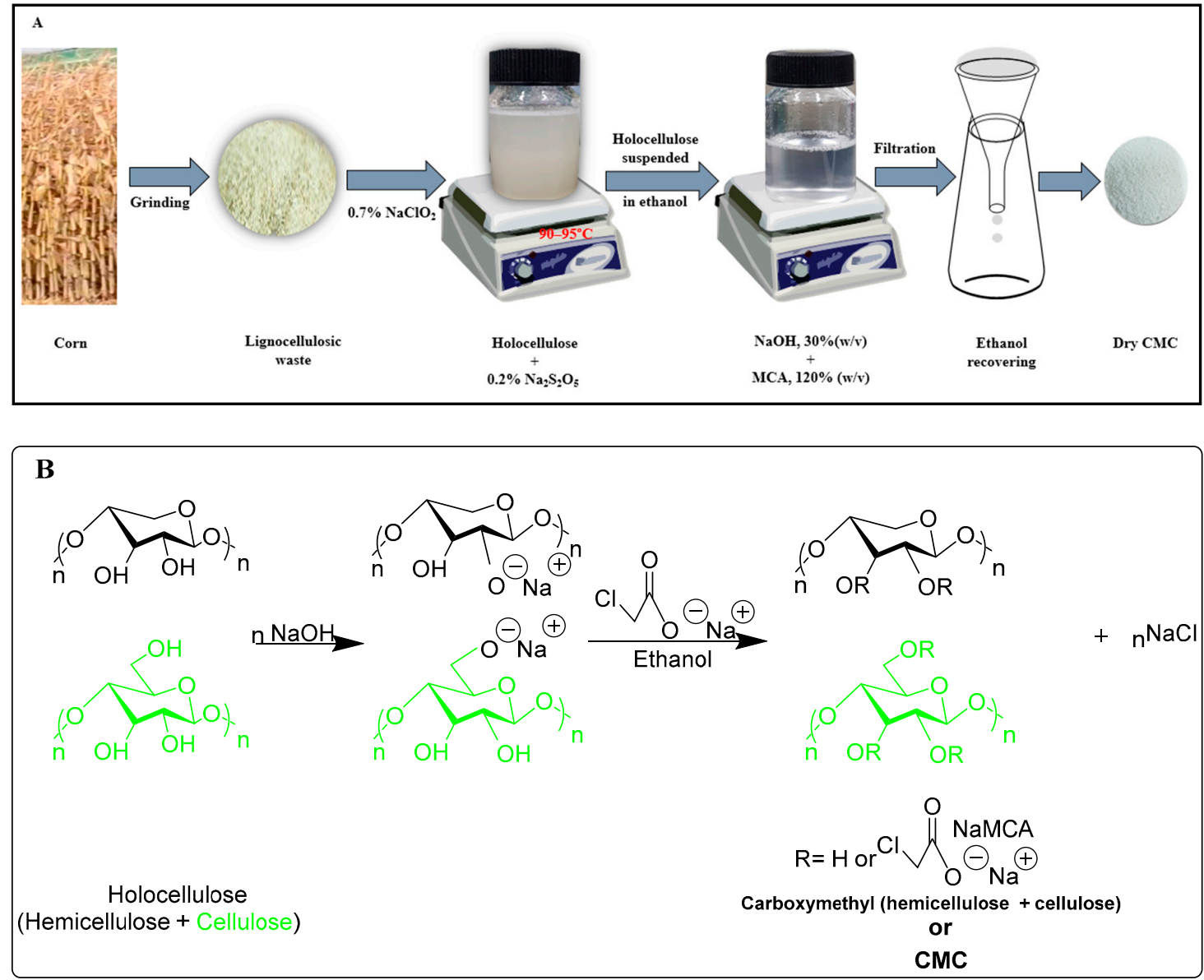

Figure 1. Schematic diagram of synthesizing of carboxymethyl cellulose (CMC) from holocellulose (A). Reaction mechanism of carboxymethylation of holocellulose (hemicellulose and cellulose) (B). 


\subsection{Estimation of Yield (\%) of CMC}

The yield of CMC was calculated based on a dry weight basis, where the weight of dried CMC was divided by the weight of holocellulose:

$$
\text { CMC yield, } \%=\frac{y}{x} \times 100,
$$

where $y$ and $x$ is the weight of moisture-free CMC (g) and holocellulose $(\mathrm{g})$, respectively.

\subsection{Determination of Degree of Substitution (DS)}

Before the determination of DS, the prepared CMC was acidified by using the modified protocols as described elsewhere [22,23]. Briefly, $2 \mathrm{~g}$ of CMC powder was placed in $100 \mathrm{~mL}$ of a beaker, and $40 \mathrm{~mL}$ of $95 \%$ ethanol was added, followed by $10 \mathrm{~min}$ agitation. Then, $2.5 \mathrm{~mL}$ of nitric acid was added and the solution was boiled in a hotplate. Subsequently, after removing the solution from the hotplate, it was stirred for $15 \mathrm{~min}$. The liquid solution was decanted by using a vacuum pump and washed with $80 \%$ ethanol for several times. Then, the residue was washed with a small quantity of methanol and filtered. To analyze the DS, $1.0 \mathrm{~g}$ of dried CMC was added to $100 \mathrm{~mL}$ of distilled water, and $12.50 \mathrm{~mL}$ of $1 \mathrm{~N} \mathrm{NaOH}$ was added with agitation. After completely dissolving the mixture, it was then titrated by $1 \mathrm{~N} \mathrm{HCl}$ in the presence indicator phenolphthalein. The DS of CMC was calculated by the utilization of the following equations [23]:

$$
\begin{gathered}
\mathrm{O}=\frac{\mathrm{PQ}-\mathrm{RS}}{\mathrm{T}}, \\
\mathrm{DS}=\frac{0.162 \times \mathrm{O}}{1-0.058 \times \mathrm{O}^{\prime}},
\end{gathered}
$$

where

$\mathrm{O}=$ milli-equivalents of used $\mathrm{HCl}$ per gram of specimen;

$\mathrm{P}=$ volume of $\mathrm{NaOH}$;

$\mathrm{Q}=$ concentration in the normality of $\mathrm{NaOH}$;

$\mathrm{R}=$ volume of consumed $\mathrm{HCl}$;

$\mathrm{S}=$ concentration in normality of $\mathrm{HCl}$;

$\mathrm{T}=$ specimen grams;

162 is the molecular weight of the anhydrous glucose unit and 58 is the net increment in the anhydrous glucose unit for every substituted carboxymethyl group.

\subsection{Determination of Molecular Weight}

CMC powder was dissolved in $0.8 \mathrm{M} \mathrm{NaOH}$ aqueous solution to measure the molecular weight by using an Ostwald viscometer. From the value of intrinsic viscosity, the molecular weight of the CMC was calculated by using the Mark-Houwink-Sakurada equation i.e., [ $\eta]=\mathrm{K} \times \mathrm{M} \times \mathrm{a}$ [19]. Where $\mathrm{K}$, a, $[\eta]$, and $\mathrm{M}$ are the constant for solvent, polymer shape factor, intrinsic viscosity, and molecular weight of $\mathrm{CMC}$, respectively.

\subsection{Structural Morphological and Thermal Study}

FTIR spectrum analysis of the extracted holocellulose and synthesized CMC were performed by Fourier transform infrared (FTIR) spectroscopy (Perkin-Elmer 240C, Waltham, MA 02451, USA) in between 400 and $4000 \mathrm{~cm}^{-1}$. For surface morphology of the dried samples, they were sputter-coated with gold for $10 \mathrm{~min}$ and then analyzed by using a scanning electron microscope (SEM) (Model-S $3400 \mathrm{~N}$, VP SEM, Hitachi, Japan) using $20 \mathrm{kV}$ accelerating voltage. The thermogravimetric analyses (TGA) of the samples were carried out using a Shimadzu TGA-50 system (Kyoto 604-8511, Japan) under a nitrogen atmosphere. The heating rate was $20^{\circ} \mathrm{C} / \mathrm{min}$, and the temperature range was 25 to $600{ }^{\circ} \mathrm{C}$. 


\subsubsection{Moisture Content}

The prepared $\mathrm{CMC}$ was dried in an oven at $105^{\circ}$ for $120 \mathrm{~min}$. Following this, the dried CMC was cooled in a desiccator until the ambient temperature was reached, and the final weight was taken. The moisture content was determined by this following equation [23]:

$$
\text { Moisture content }(\%)=\frac{\mathrm{y}}{\mathrm{w}_{0}} \times 100,
$$

where $\mathrm{y}$ and $\mathrm{x}$ is the final and initial weight of $\mathrm{CMC}(\mathrm{g})$, respectively.

\subsubsection{Flow Properties of $\mathrm{CMC}$}

Flow properties of CMC were measured by performing several tests such as bulk and tap densities, true density, porosity, angle of repose, Carr's index, and Hausner's ratio. Detailed descriptions of these tests are given below.

\subsubsection{Bulk and Tap Densities}

A suitable amount of CMC powder (g) was poured in a $100 \mathrm{~mL}$ calibrated graduate cylinder and placed in a bulk density apparatus (LOGAN TAP-2S, New Jersey 08873 USA). After lightly tapping the cylinder, the occupied volume $V_{0}$ was estimated. After, that the cylinder was tapped 500 times for measuring the tap density and calculated by using the following relationship, respectively [24-26]:

$$
\begin{aligned}
& \text { Bulk density }(\mathrm{BD})=\frac{w}{V_{0}}, \\
& \text { Tap density }(\mathrm{TD})=\frac{w}{V_{500}},
\end{aligned}
$$

where $w$ is the weight of CMC powder, $V_{0}$ is volume before tapping, and $V_{500}$ is the volume of CMC powder after 500 times tapping.

\subsubsection{True Density}

The true density of the CMC powder was calculated by using a calibrated Quantachrome pycnometer (Quantachrome Corporation, FL, USA). CMC powder was dried at ambient temperature overnight under reduced pressure before analysis. True density was estimated by using the following formula $[25,26]$ :

$$
\text { True density }(\mathrm{TD})=\frac{\mathrm{w}}{\mathrm{v}}
$$

where $\mathrm{w}$ is the weight of the $\mathrm{CMC}$ powder and $\mathrm{v}$ is true volume of the $\mathrm{CMC}$ powder.

\subsubsection{Porosity}

The porosity of the CMC powder was determined according to the following equation $[25,26]$ :

$$
\text { True density }(\mathrm{TD})=1-\frac{\text { tap density }}{\text { true density }} \times 100 \text {. }
$$

\subsubsection{Angle of Repose}

The angle of repose of the CMC powder was measured by using a funnel and a Petri dish. At first, the funnel was fixed with a funnel holder. For making a cone, the CMC powder was allowed to emanate freely through the funnel. The height and diameter of the cone were recorded by a measuring scale and determined by using the following formula $[25,26]$ : 


$$
\tan \theta=\frac{2 \mathrm{~h}}{\mathrm{D}}
$$

where $D$ is diameter of the cone and $\mathrm{h}$ is the height of the cone.

\subsubsection{Carr's Index and Hausner's Ratio}

The Carr's index (CI) [25] and the Hausner ratio (HR) [26] were estimated by using the value tap and bulk density:

$$
\begin{gathered}
\mathrm{CI}=\frac{\text { tap density }- \text { bulk density }}{\text { tap density }} \times 100, \\
\mathrm{HR}=\frac{\text { tap density }}{\text { bulk density }} .
\end{gathered}
$$

\section{Results and Discussion}

\subsection{Chemical Composition, DS, Yield, and Molecular Weight of CMC}

The chemical composition of corn waste residue including holocellulose (i.e., $\alpha, \beta$, and $\gamma$-cellulose), lignin, pectic matter, fatty and waxy matter were estimated, and their results are shown in Table 1. From Table, it can be observed that the $\alpha$-cellulose contents (i.e., $41.2 \%$ ) were dominant among all other constituents, followed by $\beta$-cellulose and $\gamma$-cellulose contents. The amount of lignin, fatty and waxy matter, and pectic matters were $19.4 \%, 2.6 \%$, and $3.6 \%$, respectively. However, all types of holocellulose (i.e., $\alpha, \beta$, and $\gamma$-cellulose) were converted into CMC through carboxymethylation. The synthetic route and reaction mechanism of synthesizing CMC from holocellulose is depicted in Figure 1.

\begin{tabular}{|c|c|c|c|c|c|c|}
\hline \multicolumn{3}{|c|}{ Holocellulose } & \multirow[b]{2}{*}{$\begin{array}{l}\text { Lignin, } \\
\text { wt } \%\end{array}$} & \multirow[b]{2}{*}{$\begin{array}{c}\text { Fatty and Waxy } \\
\text { Matters, wt } \%\end{array}$} & \multirow[b]{2}{*}{$\begin{array}{c}\text { Pectic Matters, } \\
\text { wt } \%\end{array}$} & \multirow[b]{2}{*}{$\begin{array}{c}\text { Others, } \\
\text { wt } \%\end{array}$} \\
\hline $\begin{array}{c}\alpha \text {-Cellulose, } \\
\text { wt } \%\end{array}$ & $\begin{array}{c}\beta \text {-Cellulose, } \\
\text { wt } \%\end{array}$ & $\begin{array}{c}\gamma \text {-Cellulose, } \\
\text { wt } \%\end{array}$ & & & & \\
\hline $41.2 \pm 1.1$ & $15.2 \pm 0.9$ & $14.7 \pm 1.0$ & $19.4 \pm 1.4$ & $2.6 \pm 0.2$ & $3.6 \pm 0.3$ & $3.3 \pm 0.5$ \\
\hline
\end{tabular}

Table 1. Composition of corn waste residue (Each test was performed at least three times and average and standard deviation were considered).

Corn wastes were converted into CMC depending on different particle sizes. The values of DS, yield (wt \%), and molecular weight of the obtained CMC are illustrated in Figures $2-4$ respectively. From Figure 2, it can be seen that the DS of the prepared CMC was greatly dependent on the particle size of the starting material (holocellulose). Therefore, it shows a trade-off relationship with the particle size of the holocellulose i.e., the values of DS gradually increased with the decreasing size of the holocellulose. The highest DS value of 1.83 was obtained from the lowest particle size of $100 \mu \mathrm{m}$.

The highest yield (i.e., $182.55 \%$ ) of CMC was found with the lowest particle size of holocellulose i.e., $100 \mu \mathrm{m}$, whereas the yield declined with increasing particle size of holocellulose (Figure 3). One might postulate that we have reported a higher yield of CMC in this study. This was highly desirable as the anhydrous glucose unit (molecular weight $162 \mathrm{~g} / \mathrm{moL}$ ) substituted into the sodium carboxymethyl groups (molecular weight $80 \mathrm{~g} / \mathrm{moL}$ ) based on the DS value. Therefore, the higher yield was highly desirable. However, we did a theoretical calculation and compared the data with the experimental findings. We found that theoretical yield was slightly higher (i.e., 7.0-8.6\%) for theoretical mass yield, which indicated that successful substitution of the hydroxyl groups occurred by the sodium carboxymethyl groups. This result shows the resemblance with the principle that the reduced particle generates a larger surface area, which increases the chance of collisions between reactants and holocellulose. Therefore, the yield of CMC was increased by decreasing the holocellulose particle sizes [27]. 
From Figure 4, it can be noticed that the molecular weight of the prepared CMCs was significantly increased with the increasing DS value. From Figure 2, it was mentioned that the DS value was increased with the decreasing of holocellulose particle size. Since the smaller holocellulose particle size has a greater surface area, the excessive amount of reactants can infiltrate into the holocellulose at a time. In addition, Wang et al. mentioned that the etherification process significantly relies on the availability of the activated hydroxyl groups of AGU as well as the approachability of reactants [28]. Thus, higher DS, as well as molecular weight, were obtained due to the increasing number of -OH groups substituted by the sodium carboxymethyl group. The highest molecular weight of 457,910 Da was obtained with DS value of 1.83, whereas the lowest molecular weight of 100,388 Da was yielded with DS value of 0.34 , as depicted in Figure 4 . The molecular weight of the AGU was $162 \mathrm{~g} / \mathrm{mol}$, and the net gain in the AGU for every substituted sodium carboxymethyl group was $80 \mathrm{~g} / \mathrm{mol}$. Likewise, the carboxymethyl group is weightier than the $-\mathrm{OH}$ group, hence, the molecular weight of the CMC increased [23].

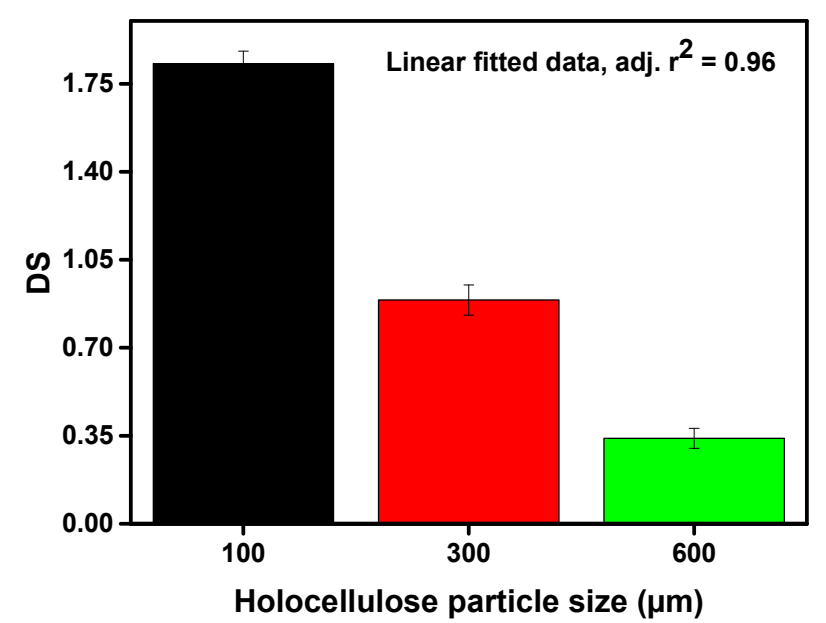

Figure 2. Degree of substitution of the synthesized CMC depending on varying particle size of holocellulose.

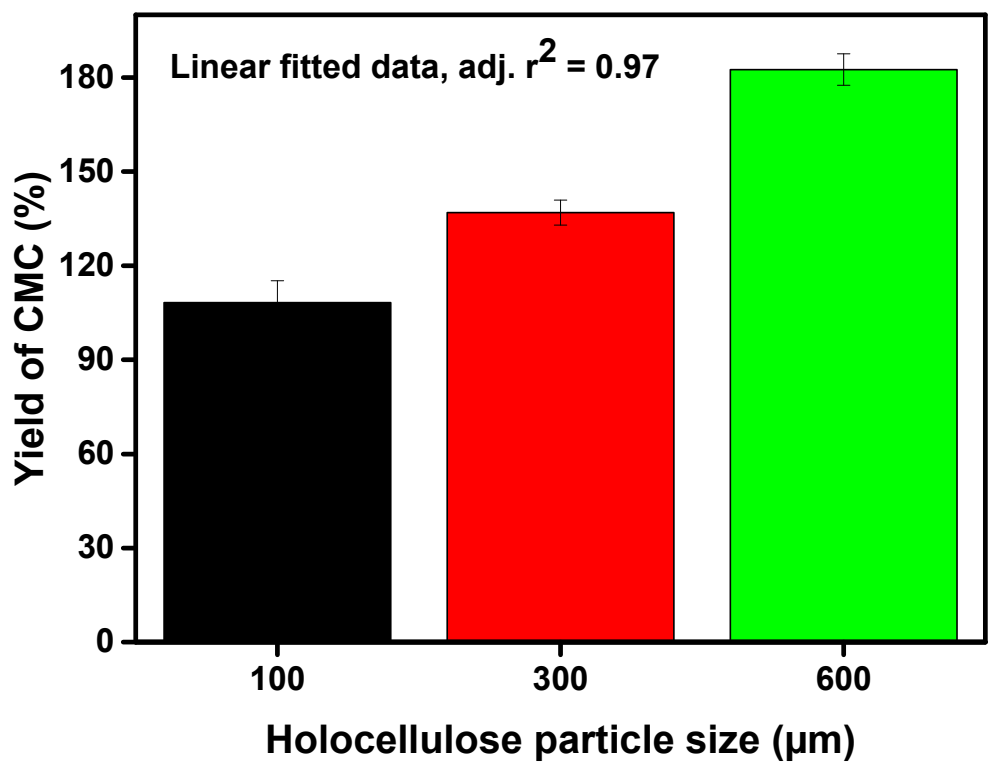

Figure 3. Converted amount of CMC as yield (wt\%) via varying particle size of holocellulose. 


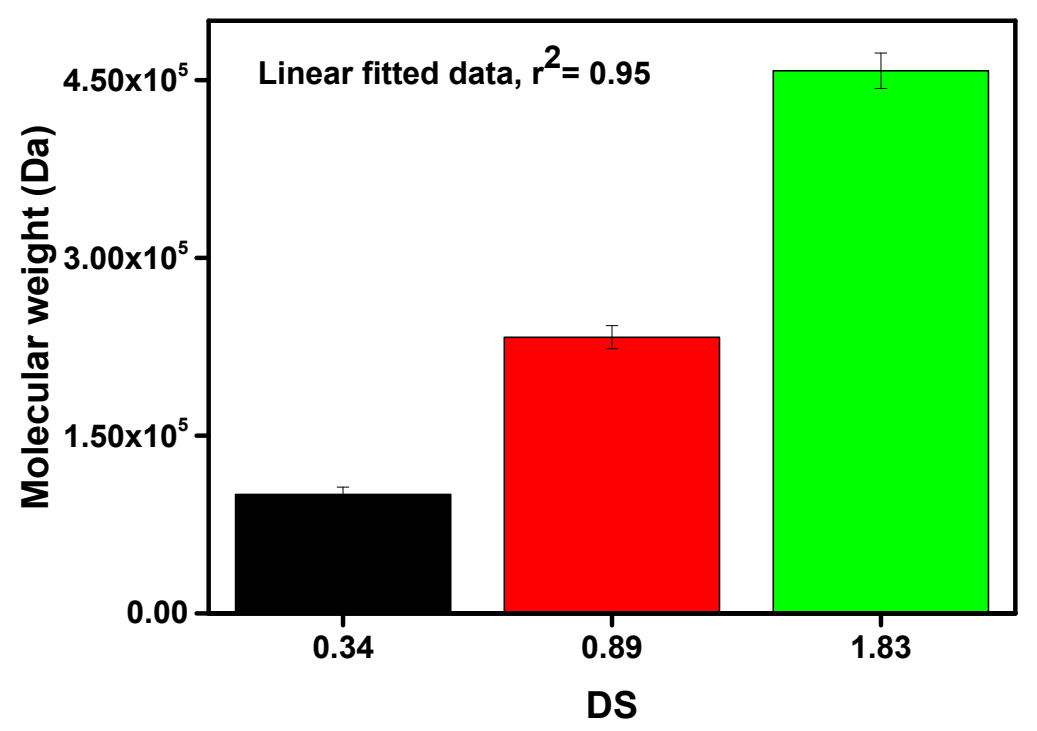

Figure 4. Estimation of molecular weight of prepared carboxymethyl cellulose (CMC) with different degrees of substitution value.

\subsection{Structural Characterization}

Different characterization techniques were used to characterize the synthesized CMC and holocellulose extracted from corn waste. For example, FTIR spectroscopy was used to analyze the surface functional groups present in the extracted holocellulose and synthesized CMC (Figure 5). From the FTIR spectra of the corn wastes powder and holocellulose, a distinct difference was noticed. Significant differences were observed in the wavenumber in between 1800 and $1000 \mathrm{~cm}^{-1}$. Several peaks such as at wavenumber $1741 \mathrm{~cm}^{-1}$ (due to $\mathrm{C}=\mathrm{O}$ stretching), $1637 \mathrm{~cm}^{-1}$ (due to carbonyl stretching conjugate with aromatic rings), and $1513 \mathrm{~cm}^{-1}$ (due aromatic $\mathrm{C}=\mathrm{C}$ stretch) were not found in the extracted holocellulose [29]. Most specifically, peak at wavenumber $1250 \mathrm{~cm}^{-1}$ (due to C-O stretching vibration) was significantly reduced, and peak at wavenumber $1513 \mathrm{~cm}^{-1}$ (due to aromatic $C=C$ stretch) was absent in the holocellulose. This phenomenon indicated that the lignin was removed during the extract process [30]. On the other hand, the wavenumbers at around 1423 and $1640 \mathrm{~cm}^{-1}$ were due to $-\mathrm{CH}_{2}$ bending and $\mathrm{O}-\mathrm{H}$ bending vibration of the absorbed water, respectively [31].

From the spectra of $\mathrm{CMC}$, a broad absorption band at $3436 \mathrm{~cm}^{-1}$ was found, which indicated the presence of -OH group, and a band at $2928 \mathrm{~cm}^{-1}$ was attributed to the $\mathrm{C}-\mathrm{H}$ stretching vibration $[10,32]$. In addition, a new and strong wavenumber at $1620 \mathrm{~cm}^{-1}$ was found, which confirmed the stretching vibration of carboxyl groups $\left(\mathrm{COO}^{-}\right)$, and a peak at $1424 \mathrm{~cm}^{-1}$ assigned to the salts of carboxyl groups [22]. The peaks at around 1327 and $1116 \mathrm{~cm}^{-1}$ can be assigned to $-\mathrm{OH}$ bending vibration and $-\mathrm{C}-\mathrm{O}-\mathrm{C}$ stretching, respectively. A wavelength of $898 \mathrm{~cm}^{-1}$ was found, which was due to 1 and $4-\beta$ glycosides of cellulose [11].

For the characterization of cellulose-based materials, SEM is one of the general techniques for imaging the microstructure and morphology of the materials. The morphologies of isolated holocellulose and synthesized CMC were also observed using an optical microscope, depicted in Figure 6. Ribbon shaped or rod-like morphology was found for the synthesized CMC, which is similar with the reported literature [33]. Furthermore, from Figure 6, it can also be observed that the surface morphology of extracted holocellulose is smoother with very low damage. In contrast, the morphology of the prepared CMC was more extended, rough, and collapsed [34]. In addition, the isolated holocellulose was further treated with sodium hydroxide during carboxymethylation, thus the ruptured surface was obtained from the synthesized CMC [35]. From Figure 6, it can be found that the size of the particles of holocellulose and CMC were in the range of 1.0-3.5 and 1.5-3.5 $\mu \mathrm{m}$ (approximately), respectively. 


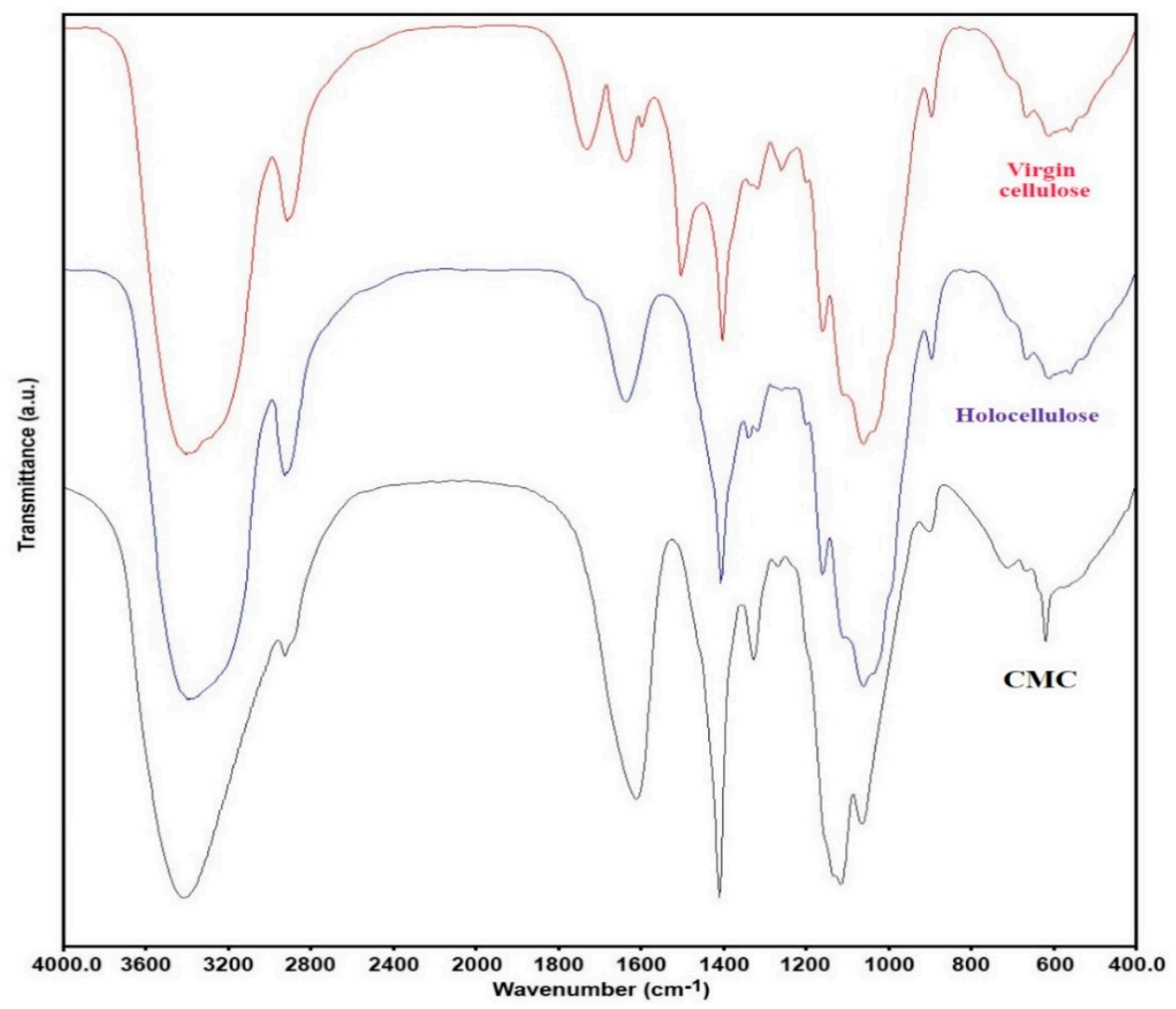

Figure 5. Structural properties of holocellulose and CMC (with degree of substitution 1.83). FTIR spectra of virgin cellulose, isolated holocellulose, and synthesized CMC.
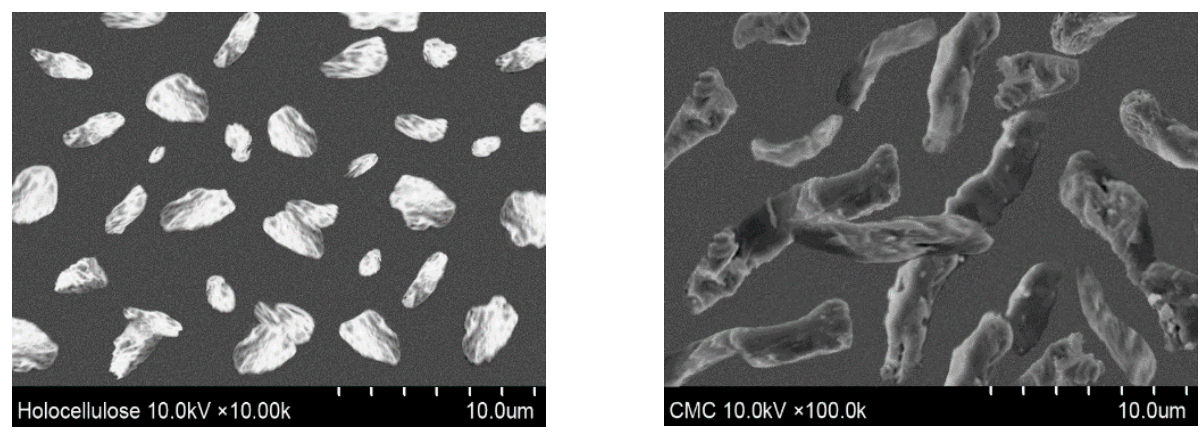

Figure 6. Surface morphology of isolated holocellulose and synthesized CMC (with DS 1.83).

XRD analysis is one of the prime methods of physical research. This technique was employed to investigate the degree of crystallinity before and after the carboxymethylation of cellulose [36]. $\mathrm{XRD}$ analysis of the samples is presented in the Figure 7. The obtained peaks of the samples were analogous to both crystalline and amorphous phases [37]. From the figure, it can be inferred that that holocellulose is more crystalline than CMC. More clearly, holocellulose gave five peaks at $2 \theta=14.2^{\circ}$, $22.1^{\circ}, 27.4^{\circ}, 31.6^{\circ}$, and $45.4^{\circ}$ and the peaks were sharp, which indicated the presence of more crystalline phases on its core structure. On the other hand, in the CMC diffractogram, less number of peaks were found after carboxymethylation in comparison with the diffractogram of holocellulose in Figure 7. Therefore, the presence of more amorphous structures in the CMC compared to holocellulose can be seen since the characteristic peaks at $2 \theta=14.2^{\circ}, 22.1^{\circ}$, and $27.4^{\circ}$ became broader and intensity was reduced significantly. In addition, it can be observed that the typical peak at $2 \theta=31.6^{\circ}$ for extracted holocellulose disappeared in CMC [9]. On the contrary, the peak at $2 \theta=45.4^{\circ}$ reduced dramatically for $\mathrm{CMC}$. This was due to the decrease in crystallinity in CMC as holocellulose was transformed from 
the crystalline to highly amorphous phase after carboxymethylation [38]. Furthermore, the peak at $2 \theta=14.2^{\circ}$ still appeared in CMC, which indicated the presence of some sort of crystallinity, although the peak intensity was not sharp enough as holocellulose. Even though the percentage of crystallinity of synthesized CMC was not quantitatively determined, it can be supposed that the CMC adopted a disordered arrangement as compared to isolated holocellulose. This characteristic can be attributed to the presence of the carboxymethyl moieties which substituted the hydrogen atoms of the hydroxyl groups of cellulose [39]. Finally, holocellulose was treated with the alkaline solution during the carboxymethylation process, and as a result they swelled and showed tension with neighboring crystallites of cellulose molecules [40].

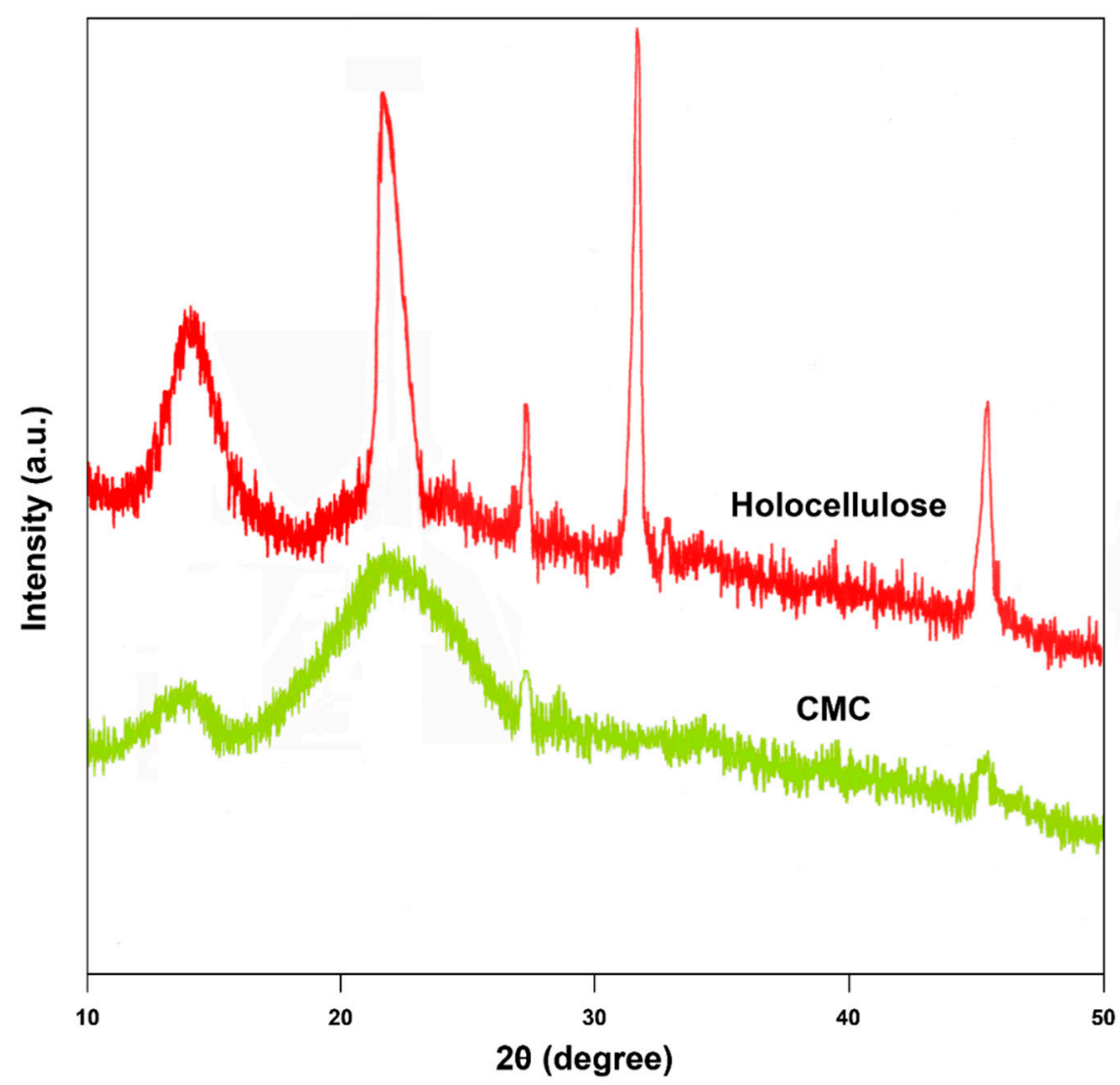

Figure 7. X-ray diffractogram of extracted holocellulose and synthesized CMC (with degree of substitution of 1.83).

TGA is a technique by which the thermal stability of a material can be analyzed, where the material is decomposed by the heat, and bonds are broken within the molecule [41]. During the test, when the maximum degradation occurs at a certain temperate, it is considered as an indicator of the stability of the material. The TGA graph of holocellulose and CMC is shown in Figure 8. From the figure, the weight loss of moisture, volatile compounds, and carbohydrate polymers during the carbonization phase can be observed.

According to the figure, $2.3 \%$ weight loss was observed in the case of holocellulose. This was due to evaporation of absorbed water. Lin et al. [42] reported that the decomposition temperatures of hemicellulose and cellulose were in the ranges of $200-315^{\circ} \mathrm{C}$ and $360-400{ }^{\circ} \mathrm{C}$, respectively. In our case, we observed the degradation stage of hemicellulose and cellulose in the ranges of $\sim 300^{\circ} \mathrm{C}$ and $\sim 380-400{ }^{\circ} \mathrm{C}$, respectively. The weight loss of holocellulose was around $79 \%$ in the temperature range of 340 to $387^{\circ} \mathrm{C}$, but holocellulose started to degrade at around $300{ }^{\circ} \mathrm{C}$, which was due to the thermal decomposition of glycoside linkages of cellulose (i.e., hemicellulose). In addition, the final change was observed after $380^{\circ} \mathrm{C}$, which was due to the decomposition of $\alpha$-cellulose [43,44]. 


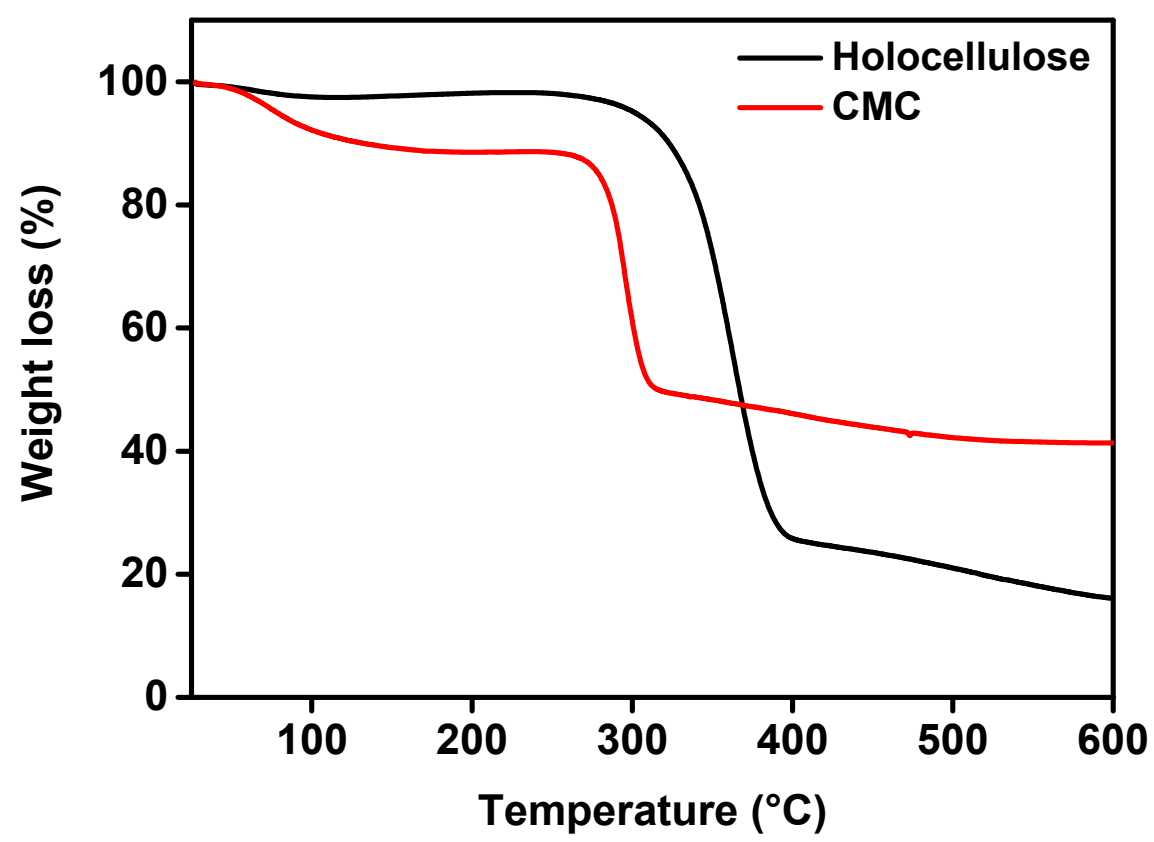

Figure 8. TGA curves of holocellulose and synthesized CMC (with degree of substitute 1.83).

On the other hand, CMC contained about $11.0 \%$ moisture. This primarily indicates that the CMC was more hygroscopic, and this is basically due to the presence of the carboxyl groups. The main decomposition of synthesized CMC was initiated at above $100{ }^{\circ} \mathrm{C}$. This was due to the release of moisture from the $\mathrm{CMC}$ by the breaking of the hydrogen bond. Subsequently, the second and third stages decomposition was held between 283 and $318{ }^{\circ} \mathrm{C}$. Finally, the weight loss was about $40 \%$, which was probably due to the depolymerization of $\mathrm{CMC}$ by forming $\mathrm{H}_{2} \mathrm{O}, \mathrm{CO}, \mathrm{CO}_{2}$, and $\mathrm{CH}_{4}$ [45]. In the temperature of 283 and $318^{\circ} \mathrm{C}, \mathrm{CMC}$ was decarboxylated as it contained $\mathrm{COO}^{-}$groups in their structure. In addition, as shown in Figure 8, the thermal decomposition temperature further occurred from about 318 to $377^{\circ} \mathrm{C}$, which indicated a further loss of the mass up to $42.2 \%$. The rate of weight loss gradually enhanced with the increase in temperature. This indicated the presence of more non-volatile fraction in CMC. More clearly, from the previous discussion, we confirmed that CMC had more irregular fractions of the amorphous structure, together with the sodium carboxymethyl unit. This unit was quite tough to break down at the referred temperature. Therefore, we assume that CMC should have higher stability than holocellulose (mass basis). This was mainly due to the presence of sodium ions in the residual mass, the degradation is quite tough. Henceforth, the mass residual mass (in the form of char) was expected to increase significantly, together with higher degradation temperature [46,47]. Therefore, in our case, we found that around $42.2 \%$ residual mass was even at a higher temperature compared to the holocellulose residual mass (i.e., $21 \%$ ).

\subsection{Feasibility as Pharmaceuticals Excipient}

Generally, microcrystalline cellulose is being used as excipient, which is extracted from hardwood and also from purified cotton. This process is considered an expensive process. Therefore, investigations are going on to find out the cheaper resources like CMC [19]. In general, the excipient has no medicinal functions. Excipients are being utilized in many ways in the pharmaceutical industries. They can be used as a binder, disintegrator, coating material, diluent, lubricant, and so on [19]. Especially, during the manufacturing of tablets, physical parameters of the excipient plays a crucial role. Herein, we compared the physicochemical characteristics of synthesized CMC with commercial CMC (as excipient). The physicochemical characteristics of synthesized CMC powder and commercial CMC are shown in Table 2. Moisture content plays a crucial role in the case of flow properties of the powder. The effect of moisture on powder flowability depends on the amount of water and its distribution. It is quite 
common that the flowability of the powder often decreases with the increase of moisture content. Because a higher amount of water will increase the thickness of the adsorbed liquid layer, it increases the strength of liquid bridges. As a result, the powder becomes more cohesive and tends to form agglomerates [48]. It is clear from the table that the physicochemical properties of synthesized CMC power remained within acceptable limits with not more than $10 \%$ variations [49]. However, the bulk density rendered an estimate of the ability of a material to flow, which is related to compressibility.

Table 2. Physicochemical characteristics of synthesized CMC as an excipient.

\begin{tabular}{ccc}
\hline Characteristics & CMC Powder (with DS 1.83) & CMC Powder (Excipient Grade with DS 0.9) \\
\hline Moisture content & $1.36 \pm 0.00$ & $0.94 \pm 0.01$ \\
Bulk density $(\mathrm{g} / \mathrm{mL})$ & $0.50 \pm 0.004$ & $0.52 \pm 0.003$ \\
Tap density $(\mathrm{g} / \mathrm{mL})$ & $0.51 \pm 0.003$ & $0.55 \pm 0.001$ \\
True density $(\mathrm{g} / \mathrm{mL})$ & $1.75 \pm 0.007$ & $1.84 \pm 0.005$ \\
Porosity & 70.82 & 80.03 \\
Angle of repose & $38.55 \pm 1.70$ & $41.27 \pm 1.20$ \\
Carr's index & $8.14 \pm 1.20$ & $7.24 \pm 1.10$ \\
Hausner's ratio & $1.37 \pm 0.010$ & $1.18 \pm 0.004$ \\
\hline
\end{tabular}

Each test was performed at least three times and average and standard deviation were considered. On the other hand, the tap density is a measure of the property of any sample of how well a powder can be packed in a confined space on recurring tapping. Bulk and tap density values of synthesized CMC showed almost similar behavior with the commercial CMC, as depicted in Table 2. It is generally considered that the better the potential for a material to flow and to re-arrange under compression, the higher the bulk and tapped densities [50]. In general, the higher true density of a powder reflects the better compressibility. The true density of synthesized CMC powder was approximately the same compared with commercial CMC. The total porosity or void fraction of a powder is the measurement of the void or empty space between the particles as well as pores within the particles of a material. In addition, it is a fraction of the volume of the void over the total volume, between $0-1$ or as a percentage between $0-100 \%$. The porosity value of the synthesized CMC was similar to the commercial $\mathrm{CMC}$, which reveals the presence of poly-sized particles. Hence, synthesized CMC can easily be compressed during tablet making. The angle of repose of powder is another important criterion that gives a qualitative assessment of its internal and cohesive frictions. Angles of up to $40^{\circ}$ show reasonable flow potential of the solid powders. On the other hand, samples with angles greater than $50^{\circ}$ exhibit poor or absent flow [51]. In this study, the angle of repose of the synthesized CMC was found to be 38.5, which indicates there was no significant difference when compared with commercial CMC. To evaluate the flow properties of the powder, the Carr index and Hausner ratio have been commonly used. Carr's compressibility index exerts a clue of how much powder can be compressed, whereas Hausner index measures the cohesion between particles and the particle flows inversely with the values of the Carr index and Hausner ratio [50,52]. In the case of Carr's index, values ranged between 5 to 10, 12 to 16,18 to 21 , and 23 to 28, indicating excellent, good, fair and poor flow properties of the material, respectively [50]. The Carr's index of the synthesized CMC powder lies in the range of 5 to 10, which indicates its excellent flow properties. By contrast, the Hausner ratio $(<1.20)$ often indicates good flowability of material, whereas a value of 1.5 or higher suggests a poor flow display by the material [52]. The Hausner ratio of the synthesized CMC showed a good flow property with value at around 1.3 in comparison with commercial CMC. Finally, it can be inferred from the discussion that the newly synthesized CMC from the agro waste can be a great source of commercial excipient.

\section{Conclusions}

CMC was successfully synthesized from extracted holocellulose. The highest yield of $182.55 \%$ was obtained with lower particle size $(100 \mu \mathrm{m})$ of the holocellulose. The higher yield was reported due to the smaller particle sizes with DS of 1.83 , which significantly contributed to incorporate 
more carboxylic groups in the CMC. Hence, it was used as a starting material for CMC synthesis. Different characterization analyses showed that CMC was successfully synthesized with ideal structural, morphological, as well as thermal properties. It was also found that the synthesized CMC had a good pharmaceutical excipient compatibility with a commercial excipient. The synthesized CMC with DS value of 1.83 can be a promising pharmaceutical excipient than other $\mathrm{CMC}$ bases excipients. Hence, this study has shown an efficient way of converting corn waste (lignocellulosic biomass) into value-added material, which can be a great aspect to be used as a pharmaceutical excipient, together with further applicability in real industrial application such as tablet making and other fields.

Author Contributions: Data curation, M.S.R. and M.S.Y.; Formal analysis, M.S.R., M.A.H. and M.B.A.; Investigation, M.S.R.; Methodology, M.S.R.; Resources, M.I.H.M. and M.S.Y.; Software, M.S.R., M.S.Y., M.A.H. and M.A.B.; Supervision, M.I.H.M. and M.A.S.; Writing-original draft, M.S.R.; Writing-review and editing, M.I.H.M. and M.B.A. All authors have read and agree to the published version of the manuscript.

Funding: This research received no external funding.

Conflicts of Interest: The authors declare no conflict of interest.

\section{References}

1. Dong, H.; Zheng, L.; Yu, P.; Jiang, Q.; Wu, Y.; Huang, C.; Yin, B. Characterization and application of lignin-carbohydrate complexes from lignocellulosic materials as antioxidants for scavenging in vitro and in vivo reactive oxygen species. ACS Sustain. Chem. Eng. 2020, 8, 256-266. [CrossRef]

2. Arora, A.; Nandal, P.; Singh, J.; Verma, M.L. Nanobiotechnological advancements in lignocellulosic biomass pretreatment. Mater. Sci. Energy Technol. 2020, 3, 308-318. [CrossRef]

3. Tigchelaar, M.; Battisti, D.S.; Naylor, R.L.; Ray, D.K. Future warming increases probability of globally synchronized maize production shocks. Proc. Natl. Acad. Sci. USA 2018, 115, 6644-6649. [CrossRef] [PubMed]

4. Zhang, Y.; Ghaly, A.E.; Li, B. Physical Properties of Corn Residues. Am. J. Biochem. Biotechnol. 2012, 8, 44-53.

5. Lin, W.; Xing, S.; Jin, Y.; Lu, X.; Huang, C.; Yong, Q. Insight into understanding the performance of deep eutectic solvent pretreatment on improving enzymatic digestibility of bamboo residues. Bioresour. Technol. 2020, 306, 123163. [CrossRef]

6. Giuliano, A.; Barletta, D.; De Bari, I.; Poletto, M. Techno-economic assessment of a lignocellulosic biorefinery co-producing ethanol and xylitol or furfural. Comput. Aided Chem. Eng. 2018, 43, 585-590.

7. Rop, K.; Mbui, D.; Njomo, N.; Karuku, G.N.; Michira, I.; Ajayi, R.F. Biodegradable water hyacinth cellulose-graft-poly (ammonium acrylate-co-acrylic acid) polymer hydrogel for potential agricultural application. Heliyon 2019, 5, e01416. [CrossRef] [PubMed]

8. Lin, W.; Chen, D.; Yong, Q.; Huang, C.; Huang, S. Improving enzymatic hydrolysis of acid-pretreated bamboo residues using amphiphilic surfactant derived from dehydroabietic acid. Bioresour. Technol. 2019, 293, 122055. [CrossRef]

9. Klemm, D.; Heublein, B.; Fink, H.P.; Bohn, A. Cellulose: Fascinating biopolymer and sustainable raw material. Angew. Chem. 2005, 44, 3358-3393. [CrossRef]

10. Santos, D.M.D.; Bukzem, A.D.L.; Ascheri, D.P.R.; Signini, R.; Aquino, G.L.B.D. Microwave-assisted carboxymethylation of cellulose extracted from brewer's spent grain. Carbohydr. Polym. 2015, 131, 125-133. [CrossRef] [PubMed]

11. Rose, G.P.; Viera, G.R.F.; De Rosana, A.M.N.; Da Carla, S.M.; Julia, G.V. Synthesis and characterization of methyl cellulose from sugar cane bagasse cellulose. Carbohydr. Polym. 2007, 67, 182-189.

12. He, X.; Wu, S.; Fua, D.; Nia, J. Preparation of sodium CMC from paper sludge. J. Chem. Technol. Biotechnol. 2009, 84, 427-434. [CrossRef]

13. Gulati, I.; Park, J.; Maken, S.; Lee, M.G. Production of carboxymethylcellulose fibers from waste lignocellulosic sawdust using $\mathrm{NaOH} / \mathrm{NaClO}_{2}$ pretreatment. Fiber. Polym. 2014, 15, 680-686. [CrossRef]

14. Nagieb, Z.; Sakhawy, M.E.; Samir, K. Carboxymethylation of cotton linters in alc. Medium. Int. J. Polym. Mater. 2001, 50, 163-173. [CrossRef]

15. Yang, X.H.; Zhu, W.L. Viscosity properties of sodium carboxymethylcellulose solutions. Cellulose 2007, 14, 409-417. [CrossRef] 
16. Almlöf, H.; Schenzel, K.; Germgård, U. Carboxymethyl Cellulose Produced at Different Mercerization Conditions and Characterized by NIR FT Raman Spectroscopy in Combination with Multivariate Analytical Methods. Bioresources 2013, 8, 1918-1932.

17. Khullar, R.; Varshney, V.K.; Naithani, S.; Heinze, T.; Soni, P.L. Carboxymethylation of Cellulosic Material (Average Degree of Polymerization 2600) Isolated from Cotton(Gossypium) Linters with Respect to Degree of Substitution and Rheological Behavior. J. Appl. Polym. Sci. 2005, 96, 1477-1482. [CrossRef]

18. Dürig, T.; Karan, K. Binders in Wet Granulation, Handbook of Pharmaceutical Wet Granulation, Theory and Practice in a Quality by Design Paradigm; Academic Press: Cambridge, MA, USA, 2019; Chapter 9; pp. 317-349.

19. Jacques, E.R.; Alexandridis, P. Tablet Scoring: Current Practice, Fundamentals, and Knowledge Gaps. Appl. Sci. 2019, 9, 3066. [CrossRef]

20. Mondal, M.I.H.; Haque, M.M.U. Effect of grafting methacrylate monomers onto jute constituents with a potassium per sulfate initiator catalyzed by Fe (II). J. Appl. Polym. Sci. 2007, 103, 2369-2375. [CrossRef]

21. Da Silva, A.R.G.; Giuliano, A.; Errico, M.; Rong, B.G.; Barletta, D. Economic value and environmental impact analysis of lignocellulosic ethanol production: Assessment of different pretreatment processes. Clean Technol. Environ. Policy 2019, 21, 637-654. [CrossRef]

22. Bono, A.; Ying, P.H.; Yan, F.Y.; Muei, C.L.; Sarbatly, R.; Krishnaiah, D. Synthesis and characterization of carboxymethyl cellulose from palm kernel cake. Adv. Natl. Appl. Sci. 2009, 3, 5-11.

23. Mondal, M.I.H.; Alam, A.B.M.F. Utilization of cellulosic wastes in textile and garment industries: 2. Synthesis and characterization of cellulose acetate from knitted rag. J. Polym. Environ. 2013, 21, 280-285.

24. Das, S.; Mondal, S.; Ghosh, S. Interaction of cationic gemini surfactant tetramethylene-1,4bis(dimethyltetradecylammonium bromide) with anionic polyelectrolyte sodium carboxymethyl cellulose, with two different molar masses, in aqueous and aquo-organic (isopropanol) media. RSC Adv. 2016, 6, 30795-30803. [CrossRef]

25. Carr, R.L. Classifying flow properties of solids. Chem. Eng. 1965, 72, 69-72.

26. Hausner, H.H. Friction conditions in a mass of metal powder. Int. J. Powder Metall. 1967, 3, 7-13.

27. Fu, Q.S.; Xue, Y.Q.; Cui, Z.X.; Wang, M.F. Study on the Size-Dependent Oxidation Reaction Kinetics of Nanosized Zinc Sulfide. J. Nanomater. 2014, 2014, 1-8. [CrossRef]

28. Wang, Y.; Wang, X.; Xie, Y.; Zhang, K. Functional nanomaterials through esterification of cellulose: A review of chemistry and application. Cellulose 2018, 25, 3703-3731. [CrossRef]

29. Shi, J.; Xing, D.; Li, J. FTIR Studies of the Changes in Wood Chemistry from Wood Forming Tissue under Inclined Treatment. Energy Procedia 2012, 16, 758-762. [CrossRef]

30. Sun, X.F.; Xu, F.; Sun, R.C.; Fowler, P.; Baird, M.S. Characteristics of Degraded Cellulose Obtained from Steam-Exploded Wheat Straw. Carbohydr. Res. 2005, 340, 97-106. [CrossRef]

31. Chowdhury, Z.Z.; Chandran, R.; Jahan, A.; Khalid, K.; Rahman, M.M.; Al-Amin, M.; Akbarzadeh, O.; Badruddin, I.A.; Khan, T.; Kamangar, S. Extraction of Cellulose Nano-Whiskers Using Ionic Liquid-Assisted Ultra-Sonication: Optimization and Mathematical Modelling Using Box-Behnken Design. Symmetry 2019, 11, 1148. [CrossRef]

32. Basuny, M.; Ali, I.O.; El-Gawad, A.A.; Bakr, M.F.; Salama, T.M. A fast green synthesis of Ag nanoparticles in carboxymethyl cellulose (CMC) through UV irradiation technique for antibacterial applications. J. Sol-Gel Sci. Technol. 2015, 75, 530-540. [CrossRef]

33. Klinpituksa, P.; Kosaiyakanon, P. Superabsorbent polymer based on sodium carboxymethyl cellulose grafted polyacrylic acid by inverse suspension polymerization. Int. J. Polym. Sci. 2017, 2017, 1-6. [CrossRef]

34. Rachtanapun, P.; Simasatitkul, P.; Chaiwan, W.; Watthanaworasakun, Y. Effect of sodium hydroxide concentration on properties of carboxymethyl rice starch. Int. Food Res. J. 2012, 19, 923-931.

35. Donald, A.M.; Kato, K.L.; Perry, P.A.; Waigh, T.A. Scattering Studies of the Internal Structure of Starch Granules. Starch—Stärke 2001, 53, 504-512. [CrossRef]

36. Beyene, D.; Chae, M.; Dai, J.; Danumah, C.; Tosto, F.; Demesa, A.G.; Bressler, D.C. Characterization of cellulase-treated fibers and resulting cellulose nanocrystals generated through acid hydrolysis. Materials 2018, 11, 1272. [CrossRef]

37. Park, S.; Baker, J.O.; Himmel, M.E.; Parilla, P.A.; Johnson, D.K. Cellulose crystallinity index: Measurement techniques and their impact on interpreting cellulase performance. Biotechnol. Biofuels 2010, 3, 10. [CrossRef] 
38. Parid, M.D.; Rahman, N.A.A.; Baharuddin, A.S.; Mohammed, M.A.P.; Johari, A.M.; Razak, S.Z.A. Synthesis and characterization of carboxymethyl cellulose from oil palm empty fruit bunch stalk fibres. BioRes 2018, 13, 535-554.

39. Johar, N.; Ahmad, I.; Dufresne, A. Extraction, preparation and characterization of cellulose fibres and nanocrystals from rice husk. Ind. Crop. Prod. 2012, 37, 93-99. [CrossRef]

40. Fang, J.M.; Fowler, P.; Tomkinson, J.; Hill, S. The Preparation and characterisation of a series of chemically modified potato starches. Carbohydr. Polym. 2002, 47, 245-252.

41. Loof, D.; Hiller, M.; Oschkinat, H.; Koschek, K. Quantitative and qualitative analysis of surface modified cellulose utilizing TGA-MS. Materials 2016, 9, 415. [CrossRef]

42. Lin, B.J.; Chen, W.H. Sugarcane bagasse pyrolysis in a carbon dioxide atmosphere with conventional and microwave-assisted heating. Front. Energy Res. 2015, 3, 1-9.

43. Seo, J.M.; Cho, D.; Park, W.H.; Han, S.O.; Hwang, T.W.; Choi, C.H.; Jun, S.J. Fiber surface treatments for improvement of the interfacial adhesion and flexural and thermal properties of jute/poly lactic acid biocomposites. J. Biobased Mater. Bioenergy 2007, 1, 331-340.

44. Aziz, S.H.; Ansell, M.P. The effect of alkalization and fibre alignment on the mechanical and thermal properties of kenaf and hemp bast fibre composites: Part 1-Polyester resin matrix. Compos. Sci. Technol. 2004, 64, 1219-1230. [CrossRef]

45. Durcilene, A.; Silva, D.; Paula, R.C.M.; Feitosa, J.P.A. Graft copolymerisation of acrylamide onto cashew gum. Eur. Polym. J. 2007, 43, 2620-2629.

46. Doh, S.J.; Lee, J.Y.; Lim, D.Y.; Im, J.N. Manufacturing and analyses of wet-laid nonwoven consisting of carboxymethyl cellulose fibers. Fiber. Polm. 2013, 14, 2176-2184. [CrossRef]

47. El-Sakhawy, M.; Tohamy, H.A.S.; Salama, A.; Kamel, S. Thermal properties of carboxymethyl cellulose acetate butrate. Cellulose Chem. Technol. 2019, 53, 667-675. [CrossRef]

48. Sandler, N.; Reiche, K.; Heinämäki, J.; Yliruusi, J. Effect of Moisture on Powder Flow Properties of Theophylline. Pharmaceutics 2010, 2, 275-290. [CrossRef]

49. United States Pharmacopeia and National Formulary (USP 29-NF 24); United States Pharmacopeia Convention: Rockville, MD, USA, 2007; Volume 31, p. 1349. Available online: http://www.pharmacopeia.cn/v29240/ usp29nf24s0_m13210.html (accessed on 16 May 2020).

50. Carr, R.L. Evaluating flow properties of solids. Chem. Eng. 1965, 72, 163-168.

51. Fowler, H.W. Powder flow and compaction. In Cooper and Gunn's Tutorial Pharmacy, 6th ed.; Carter, S.J., Ed.; CBS Publishers: Delhi, India, 2000.

52. Wells, J.I. Pharmaceutical Preformulation: The Physicochemical Properties of Drug Substances, 1st ed.; John Wiley and Sons: New York, NY, USA, 1988.

(C) 2020 by the authors. Licensee MDPI, Basel, Switzerland. This article is an open access article distributed under the terms and conditions of the Creative Commons Attribution (CC BY) license (http://creativecommons.org/licenses/by/4.0/). 